\title{
Male Violence Against Women: An Exploratory Study of Its Manifestations, Causes, and Discrepancies over Jordanian Women under Corona Pandemic
}

Dr. Yousef Damen Khataybeh Associate professor of sociology

Al-Balqa Applied University +962772077892

Jordan-Amman

Email: y.katibh@bau.edu.jo

Contact: Yousef Damen Ali Al Khataybeh/y.katibh@bau.edu.jo/ Department of Social Science and Humanities Al-Balqa Applied University. Amman- Jordan/ +962772077892. The Author Google Scholar Link: https://scholar.google.com/citations?user=e3ySxJifDl0C\&hl=ar

Research Interest: Problems of Family and Youth, Extremism and Terrorism, Social Community, Socio-political Studies. 


\begin{abstract}
Objectives: The study aimed to uncover the percentages of battered women in Jordan, its causes, forms, and relationship to several social factors.

Methodology: The study was conducted on a random, targeted sample of (1308) women based on social sample survey method and electronic questionnaire tool for data collection, the Descriptive statistical method and chi-square test were used to examine statistically significant differences.

Results: The study found that the percentage of battered women reached $17.1 \%$ during Corona pandemic in 2020, and the increase in men's violence against women during this period of was in large and medium degrees according to the sample. Husbands were the most practicing violence against their wives at $37.5 \%$, followed by fathers against daughters at $28.6 \%$, and brothers against sisters at $26.8 \%$. The causes of male violence are due to social factors represented by male domination culture, interference by family and relatives, and economic factors represented by the high cost of living, low household income and poverty. The most common forms of violence are verbal, physical, and psychological. The study found that women in southern Jordan, who are poorer and less educated, and who live in a large family, are the most abused. The study recommended activating family and community service and reform offices, solving problems of deteriorating economic situation and individual poverty, and enlightening community awareness of the dangers of domestic violence.
\end{abstract}

Key words: Domestic violence, crimes against women, the impact of Corona on the family, male domination, women in Jordanian culture 


\section{Introduction}

The phenomenon of violence against women is a vital topic for social and sociological studies at both local and global levels. Most of the institutional and research literature confirms its increase in various contemporary societies without exception (World Health Organization, 2020) and (National Commission for Women's Affairs, 2020), especially during Corona pandemic. This calls for concerted efforts by all concerned locally, regionally, internationally and social workers to think in greater depth to understand the phenomenon, its roots and ways to confront and prevent its growth. The volume of violence against women has escalated during Corona pandemic and occupied a large area in the speeches of many parties globally and locally, which required the researcher to carry out this scouting study in Jordan to contribute to providing international knowledge in this field.

\section{The problem of the study}

The problem of the study is determined in revealing the rates of man's violence against women, causes and forms during Corona pandemic, from perspective of a Jordanian women sample, and identifying the relationship of this violence with some social variables, such as gender, place of residence, family income, family size and educational level. It seems that violence in general is exacerbating in a way that deserves more research attention. In 2019, The Family Protection Department dealt with (14,000 cases), which reflects the size of the risks facing society and women in particular, and which increased by the end of 2020 during Corona pandemic curfew. The empirical scientific facts about it are still unknown in our society, despite statements confirming that its size has increased dramatically in Jordan.

\section{The importance of the study}

The importance of this study is determined by the fact that it sheds light on the issue of violence against women in Jordan. In theory, the study explores an existing and continuing phenomenon, but in light of the transformations of the Corona pandemic, the research required 
anew to examine the assumptions and speculative discourses about the increase in violence in a remarkable way, especially determining its rates more precisely. And the differences in the sources, causes and forms of this violence. Therefore, the study is a local, international, and humanitarian knowledge need.

The practical importance relates to the results provided by the study, in relation to the size, causes and forms of violence against women in Jordanian society, where the researcher believes that it benefits governments, community institutions, social workers and researchers, locally and internationally, and benefits program and policy makers to take into account when developing strategies to confront violence against women.

\section{Study objectives and questions}

The study aims to identify the rates, sources, and causes of violence against women during the Corona pandemic, in light of a set of social variables. Therefore, the study answers the following questions:

1.What are the percentages of battered women in Jordan? Did man's violence against women increase during Corona pandemic?

2.What are the causes, sources and forms of violence against women in Jordanian society in light of Corona pandemic?

3.Are there statistically significant differences on the causes and forms of violence against women in light of Corona pandemic due to variables of place of residence, education, family size and monthly income?

\section{Theoretical framework}

Violence is defined in the dictionary of social sciences as: "the unlawful use of control and force which affects the will of an individual" (Badawi, 1986, p. 125). Arab society is described as masculine, and the Arab family is patriarchy of a hierarchy of relationships and roles. The husband or the man is the focus of family authority (Barakat, 2011) and (Omar 2010), Under 
the rule of unequal relationships, forms of domestic violence that affect women specifically, such as anger, restriction, coercion, prohibition, expulsion, beating, threatening, and killing are produced. Accordingly, many cases of violence against women in our societies are linked to cultural standers and norms that prohibit women from foreign relations, especially sexual or romantic relations, and even consider them a "shameful disgrace" (Carron, 2020). Crimes affecting the family are classified in the culture of Arab societies, and everyone reveres the customary value of "family honour." It is related to a woman's purity and sexual chastity (Dodd, 2009). Surprisingly, in 2020 (17) murders against women were recorded in Jordan, and within 5 days of 1/2021, two girls in their twenties were killed by their brothers in the most horrific forms of criminal behaviour in the capital, Amman, just because they made phone calls with strangers.

Historically, violence appeared with the existence of man and accompanied various human societies of different cultures, races and nationalities. The forms, manifestations and size of this violence have been linked to social, cultural, political and economic factors. Perhaps violence against women is one of the most common forms in societies. The Marxist perspective explains violence towards women as a result of injustice and inequality between the sexes in rights and duties (Lutfi and Al-Zayat, 1999), the poor distribution of wealth in society and the imbalance of power (Al-Khashab, 2008), and in the monopoly, control, exploitation, bullying and slavery practiced by the strongest towards the weakest. 
This describes the reality of the status of men and women in society. In the functional perspective, violence in Arab societies is considered a product of the practicing method of social and family upbringing, values, norms, traditions and the coherence of the prevailing culture in society (Naim, 1996), some of which encourage the growth of aggressive behaviors on the part of men towards women, considering the man culturally the owner of authority, money and freedom, and women are subordinate to him lacking even to cultural support.

According to reciprocal theory, violence on women stems from marital and family instability and failure resulting from normative and cognitive trends (Al-Khashab, 1998) for both men and women based on the conflict in methods of socialization, divergence in motives and values, and the contradiction of beliefs and trends in light of unequal exchange relationships in interests and benefits. In addition, according to Al-Khatayba (2018, 2013), the problem of violence against women in all of its forms is inseparable from marital maladjustment and the Jordanian family problems related to society's capabilities and its economic, social, cultural and political conditions together, as the Arab social environment encourages the growth of violence (Al-Awda, 2018). In the shadow of women's increasing pursuit of equality and men's resistance, and their demand for more distribution of roles and work inside home, Corona pandemic and the implications of home quarantine, marital relations (Salibi et al. 2020) examined the sincerity and strength of the relationship.

\section{Violence in Jordanian society}

Profound transformations witnessed by Jordanian society during recent decades, affecting both the family and society, including changes in the patriarchal system, changes in the roles and status of women, participation in family decisions, the transformation of the family towards a small nucleus, and a change in marital relations, the system of rights, duties, values and norms that have changed in favor of Educated and working women ( Al-Khatayba 2018, 2013), influenced by the culture of expatriate societies. Changes in aspects of family sovereignty so 
that the modern wife becomes influential in various family decisions, according to the new social position in which she emerged from the traditional control of the authority of men, to gain more personal freedom and independence (Al-Zubaidi, 2020). The conflict of roles between husbands and wives, competition and love of control, the attempt to abandon family responsibility and the disagreement over the method of raising children in light of the disturbing changes to the family financially and economically, and neglect of the duties and marital rights of one of the parties (Majali and Al-Qaisi, 2002). This situation has resulted in new conflictual relations that have led to more violence rates in modern society. Accordingly, contemporary rapid societal transformations were reflected in the change in the values of the Jordanian family, its way of life, its internal roles and its interactions with the surrounding external variables, the shift towards the democracy of social life, equality and freedom, the rights of women, and the wrong understanding of the rights and duties of each of the spouses all formed fertile soil for the emergence of marital conflicts and problems (Khatayba, 2013) and this increased violence against women as a way for men to improve their behaviour (Elspeth \& Mirzoev, 2021).

\section{Previous studies}

The phenomenon of violence will always be the focus of attention of social workers, and studies about it are many and varied in terms of results, methodology, target group and the type of society. The majority indicate high rates of domestic violence and gender-based violence. A (United Nations Organization, 2020) study in the Arab region showed a significant impact of Corona pandemic on various forms of violence against women, which is one of the manifestations of gender inequality, and a tool for exercising power and control. Domestic violence rates during the pandemic lead to forced coexistence between men and women, in addition to the usual physical and emotional risks and damages that women are exposed to in some Arab countries. 
The rates of violence against women have increased in Jordan, and this result was consistent with the results of (Higher Population Council, 2020). Since the outbreak of the Corona pandemic, rates of domestic violence have increased according to $69 \%$ of the respondents. Due to forced coexistence and complete isolation with the violent, in addition to the limited services for protection from violence, and the difficulty in accessing and receiving them due to urban restrictions, during which violence increased by $33 \%$ compared to its rates in the same period last year. The number of domestic violence cases reached 1,685 cases and 17 murders against women (Family Protection, 2020). In the reviews of Petermon \& et al. (2020), it showed an increase in violence against women and children during the Corona pandemic, due to isolation measures, home quarantine, and disruption of public life, economic insecurity and the exacerbation of unemployment.

By reviewing the phenomenon of violence against women before Corona, the study (AlMajali, 2018) found that the extent of the phenomenon of violence was mostly between partial and permanent, and all forms of violence against women came in a moderate degree, where social violence was in the first place and sexual violence was in the last place, and the causes of violence against women were in the first place. Women are social, followed by political and judicial systems to a high degree. And other studies have shown (Al-Hiyasat, 2016) the most common forms of verbal and then sexual violence, as most of the battered women in Jordan were poor and uneducated, and the reasons for this violence were poverty and social media, and the interference of the husbands' parents in marital life affairs. Mansour's study (2014) showed Jordanian women are subjected to moral, social, economic, physical and sexual violence to a high degree. There are no differences between the types of violence against women due to the variable of age. While there were differences attributed to the level of education and where those who are not educated, are exposed to violence mostly. In the same 
context, other societies (Elspeth \& Mirzoev, 2021) emphasized that violence against women is linked to poverty and alcoholism, where sexual violence was the most common.

Where the apparent convergence of the roots of violence appears despite the different societies, as a study (Abdollahi et al, 2021) indicates in Iranian society that violence on the part of the husband falls on illiterate and low-educated women and in low-income families. (Al Omar 2010)showed that marital violence differs according to different experiences of conflict within the family, directed at women comes from the husband and children, followed by other parties, and it results from loss of control, lack of satisfaction, independence, fear, anxiety, threats and lack of self-esteem.

With the study of Al-Radaiaan (2008), the prevalence of social, verbal and economic violence was greater than severe violence such as physical and sexual, and the causes of violence: women attempts to give an opinion, and their extra financial demands, as well as the prevalence of the social values system that justifies violence against women and the weakness of protection systems, also victims difficulty to reach or call police, in addition to the lack of family counselling centres and the reluctance of women to seek help from those around them. Fawole (2008) indicated that the economic violence against women leads to deepening poverty, undermining educational attainment, sexual exploitation of women, trafficking in women and girls, including AIDS and other risks.

All the previous studies remain important and exciting in their results, although most of them focused on marital violence in the sense against the wife, and the current study focuses on the violence of the man that affects the woman, whether it is a husband, father, brother or co-worker, not to mention that it explores the phenomenon in during Corona pandemic.

\section{Study fields}

- The temporal domain: The study was conducted in the field during the period between $10 / 2020-2 / 2021$ 
- The human domain: The study was conducted on a sample of (1308) female respondents in Jordan.

\section{Study methodology (method and procedures)}

The study relies on the sample social survey method to detect violence against women during the Corona pandemic, and this approach is suitable for determining the characteristics of the phenomenon and describing its nature, and the quality of the relationship between its variables and its various dimensions.

\section{Study population and sample}

The study population consists of Jordanian women over the age of 18 years, a sample of (1308) women from different governorates of Jordan was selected, in a randomized, purposeful manner, through an electronic questionnaire that was sent via social media.

\section{Study tool}

The study relies on the electronic questionnaire tool as a main tool for collecting field data. The researcher designed it to achieve the goals and objectives of the study, taking into account the Arab and Jordanian cultural and social environment in particular, and it includes axes:

First axis: The sample's characteristics are the place of residence, education, family size, and monthly income.

Second axis: It consists of a set of questions that measure the rates of battered women and levels of violence in the Corona pandemic, including those relating to the social, cultural, economic, health and psychological causes of violence, as well as the forms and sources of violence.

\section{Validity and reliability of the tool}

The questionnaire was judged by five professors specializing in sociology, and to test the validity of the tool, twenty questionnaires were prepared to test the extent of its reliability in the field, and to know how to answer them, adjustments were made to some questions proven 
to be formulated in the final form. The tool reliability coefficient was calculated using the Cronbach alpha coefficient and internal consistency, after applying the questionnaire to a random sample consisting of (35), where the correlation value of the tool as a whole was (0.91), and this ratio was considered suitable for the purpose of the practical application of the questionnaire.

\section{Statistical analysis used}

The data were entered into the statistical package for social sciences (spss) and descriptive statistics (frequencies, percentages, arithmetic means, and standard deviations) were used to show the characteristics of the sample, and other dimensions of the study questions, and the chi-square was used to test the relationships between the variables of the independent study: place of residence, education, family size and family income, and the dimensions of the dependent variable: man's violence against women, the causes and forms of this violence during the Corona pandemic.

\section{Demographic characteristics of the study sample}

The majority of respondents, at a rate of $58.4 \%$, were girls, followed by $36.4 \%$ of wives and a minority of widowed and divorced women. Regarding the place of residence, $51.9 \%$ live in the central governorates, $41 \%$ live in the northern governorates, and the rest are from southern Jordan. The majority of educated women are master's degrees and above at a rate of $74.3 \%$, followed by $24.2 \%$ and a minority of secondary education and less. The sample was distributed among four age groups, the majority between 18-26 years old, and the lowest group was $9.8 \%$ whose ages ranged between $36-44$ years. As for the monthly family income, $38.5 \%$ of the family income did not exceed 500 dinars or less, while the lowest category was $11.9 \%$ of those whose family income was 1001 dinars or more (see Table 1).

Table (1) Characteristics of the study sample

\begin{tabular}{|l|l|r|}
\hline Variable & Category & Repetition \\
\hline
\end{tabular}




\begin{tabular}{|c|c|c|c|}
\hline Family relation & $\begin{array}{l}\text { daughter } \\
\text { wife } \\
\text { widow } \\
\text { divorced }\end{array}$ & $\begin{array}{c}764 \\
476 \\
40 \\
28\end{array}$ & $\begin{array}{c}58.4 \\
36.4 \\
3.1 \\
2.1\end{array}$ \\
\hline Place of resident & $\begin{array}{l}\text { North governorates } \\
\text { Central governorates } \\
\text { Southern provinces }\end{array}$ & $\begin{array}{c}536 \\
679 \\
93\end{array}$ & $\begin{array}{c}41.0 \\
51.9 \\
7.1\end{array}$ \\
\hline Education level & $\begin{array}{l}\text { secondary } \\
\text { Bachelor } \\
\text { Postgraduate }\end{array}$ & $\begin{array}{c}20 \\
316 \\
972\end{array}$ & $\begin{array}{c}1.5 \\
24.2 \\
74.3\end{array}$ \\
\hline Age & $\begin{array}{l}18-26 \\
27-35 \\
36-44 \\
45 \text { years or more }\end{array}$ & $\begin{array}{l}820 \\
148 \\
128 \\
212\end{array}$ & $\begin{array}{c}62.7 \\
11.3 \\
9.8 \\
16.2\end{array}$ \\
\hline Family monthly income & $\begin{array}{l}\text { I do not work } \\
500 \text { dinars or less } \\
501-1000 \\
1001 \text { dinars or more }\end{array}$ & $\begin{array}{l}360 \\
504 \\
288 \\
156\end{array}$ & $\begin{array}{l}27.5 \\
38.5 \\
22.0 \\
11.9\end{array}$ \\
\hline Family size & $\begin{array}{l}1-4 \\
5-8 \\
9 \text { or more individuals }\end{array}$ & $\begin{array}{l}384 \\
784 \\
140\end{array}$ & $\begin{array}{l}29.4 \\
59.9 \\
10.7\end{array}$ \\
\hline total & & \multicolumn{2}{|c|}{1308} \\
\hline
\end{tabular}

\section{Man's violence during the Corona pandemic:}

Table (2) the level of increasing violence against women during the Corona pandemic

\begin{tabular}{|l|c|c|}
\hline \multicolumn{1}{|c|}{ Level } & Repetition & ratio \\
\hline did not increase at all & 100 & 7.6 \\
\hline To a small degree & 132 & 10.1 \\
\hline Medium degree increased & 320 & 24.5 \\
\hline Significantly increased & 460 & 35.2 \\
\hline Increased very much & 296 & 22.6 \\
\hline Total & 1308 & 100.0 \\
\hline
\end{tabular}

Table (2) shows the majority of Jordanian women confirming the increase in male violence against women during the Corona pandemic, between two (high) degrees, according to $35.2 \%$ (medium) from a $24.5 \%$ perspective. Less than a quarter of women indicated that it was not increasing. The rates were very similar regarding the increase in the level of men's violence against women during the days of the comprehensive home ban, with slight variations as in Table (3).

Table (3): Men's violence against women increased more during the comprehensive home quarantine days 


\begin{tabular}{|l|c|c|}
\hline \multicolumn{1}{|c|}{ Level } & Repetition & ratio \\
\hline did not increase at all & 112 & 8.6 \\
\hline To a small degree & 128 & 9.8 \\
\hline Medium degree increased & 376 & 28.7 \\
\hline Significantly increased & 392 & 30.0 \\
\hline Increased very much & 300 & 22.9 \\
\hline Total & 1308 & 100.0 \\
\hline
\end{tabular}

The social causes of man's violence against women in Jordan

Table (4) the social causes of men's violence against women from the woman's perspective

\begin{tabular}{|l|c|c|}
\hline \multicolumn{1}{|c|}{ Reasons } & Repetition & Ratio \\
\hline The inferior view to women & 148 & 11.3 \\
\hline The culture of male authority & 656 & 50.2 \\
\hline Interfering in others' affairs & 48 & 3.7 \\
\hline Intervention of parents and relatives & 240 & 18.3 \\
\hline Women exercising their personal freedom & 60 & 4.6 \\
\hline Women betrayal & 20 & 1.5 \\
\hline Woman's lack of experience in dealing with men & 136 & 10.4 \\
\hline Total & 1308 & 100.0 \\
\hline
\end{tabular}

Table (4) data show the most important social reasons behind man's violence against women, represented in the culture of male authority at a rate of $50.2 \%$, followed by the intervention of parents and relatives in the family's life by $18.3 \%$, followed by the inferior view to women, and then the lack of experience of women in dealing with men.

\section{Health reasons for man's violence against women}

Table (5) Health causes of men's violence against women from the woman's perspective

\begin{tabular}{|l|c|c|}
\hline \multicolumn{1}{|c|}{ Reasons } & Repetition & Ratio \\
\hline husband / man illness & 224 & 17.1 \\
\hline Woman's illness & 116 & 8.9 \\
\hline Sexual maladjustment & 412 & 31.5 \\
\hline Man's muscle strength & 392 & 30.0 \\
\hline Poor hygiene for women & 164 & 12.5 \\
\hline Total & 1308 & 100.0 \\
\hline
\end{tabular}

Table (5) data: The most important health causes of male violence were sexual maladjustment

by $31.5 \%$, followed by muscle strength of men by $30 \%$, followed by illness of a husband or man.

Economic reasons for man's violence against time 
Table (6) the economic causes of men's violence against women from the woman's perspective

\begin{tabular}{|l|c|c|}
\hline \multicolumn{1}{|c|}{ Reasons } & Repetition & Ratio \\
\hline Extravagant woman overload & 72 & 5.5 \\
\hline Low level of family income & 349 & 26.7 \\
\hline Difficult living pressures & 675 & 51.6 \\
\hline Poverty & 147 & 11.2 \\
\hline Women disavow economic responsibility & 33 & 2.5 \\
\hline Women work outside the home & 32 & 2.4 \\
\hline Total & 1308 & 100.0 \\
\hline
\end{tabular}

Table (6) shows the most important economic causes of man's violence against women, represented by difficult living pressures at a rate of $51.5 \%$, followed by a low level of family income by $26.7 \%$, followed by poverty.

\section{Psychological reasons for man's violence against time}

Table (7) psychological causes of man's violence against time

\begin{tabular}{|l|c|c|}
\hline \multicolumn{1}{|c|}{ Reasons } & Repetition & Ratio \\
\hline Man's jealousy & 88 & 6.7 \\
\hline Man's mood & 526 & 40.2 \\
\hline Weakness of woman's personality & 196 & 15.0 \\
\hline Man's Aggression & 420 & 32.1 \\
\hline Suspicion & 22 & 1.7 \\
\hline Selfish woman & 56 & 4.3 \\
\hline Total & 1308 & 100.0 \\
\hline
\end{tabular}

Table (7) shows that the most important psychological causes of a man's violence against women are due to the man's mood, at a rate of $40.2 \%$, followed by the man's aggression at a rate of $32.1 \%$, followed by the weakness of woman's personality.

\section{The extent of violence against women}

Table (8) shows that the percentage of women who were abused by men in Jordan during the Corona pandemic in 2020 was $17.1 \%$, and the rest of them answered no.

Table (8): Percentage of women violated during the Corona pandemic in Jordan

\begin{tabular}{|l|c|c|}
\hline \multicolumn{1}{|c|}{ Answer } & Repetition & Ratio \\
\hline Yes & 224 & 17.1 \\
\hline No / never & 1084 & 82.9 \\
\hline Total & 1308 & 100.0 \\
\hline
\end{tabular}

Table (9): The person most practicing violence against women 


\begin{tabular}{|l|c|c|}
\hline Brother & 60 & 26.8 \\
\hline Husband & 84 & 37.5 \\
\hline Father & 64 & 28.6 \\
\hline Work Colleague & 16 & 7.1 \\
\hline Total & 224 & 100.0 \\
\hline
\end{tabular}

Table (9) shows that husbands practice more violence against their wives by $37.5 \%$, followed

by fathers against their daughters at $28.6 \%$, followed by brothers against sisters at $26.8 \%$ and the rest are work colleagues.

Table (10) forms of violence by men practicing women during 2020

\begin{tabular}{|c|c|c|}
\hline Forms Of Violence & Repetition & Ratio \\
\hline Verbal violence (cursing, reprimanding ...) & 140 & 62.5 \\
\hline Physical violence (hitting, burning, breaking ...) & 32 & 14.3 \\
\hline Psychological violence (deprivation, prevention, restriction of freedom.. & 28 & 12.5 \\
\hline Sexual violence ( exotic practices) & 4 & 1.8 \\
\hline All of the above & 20 & 8.9 \\
\hline total & 224 & 100.0 \\
\hline
\end{tabular}

Table (10) shows verbal violence is the most prevalent and practiced against women in Jordan

with a rate of $62.2 \%$, followed by physical violence, then psychological violence. The psychological effects were the most common.

Men's violence against women during home quarantine days and its relationship to some variables

Table (11) Increased men's violence against women during home quarantine days and Corona pandemic, in light of the place of residence

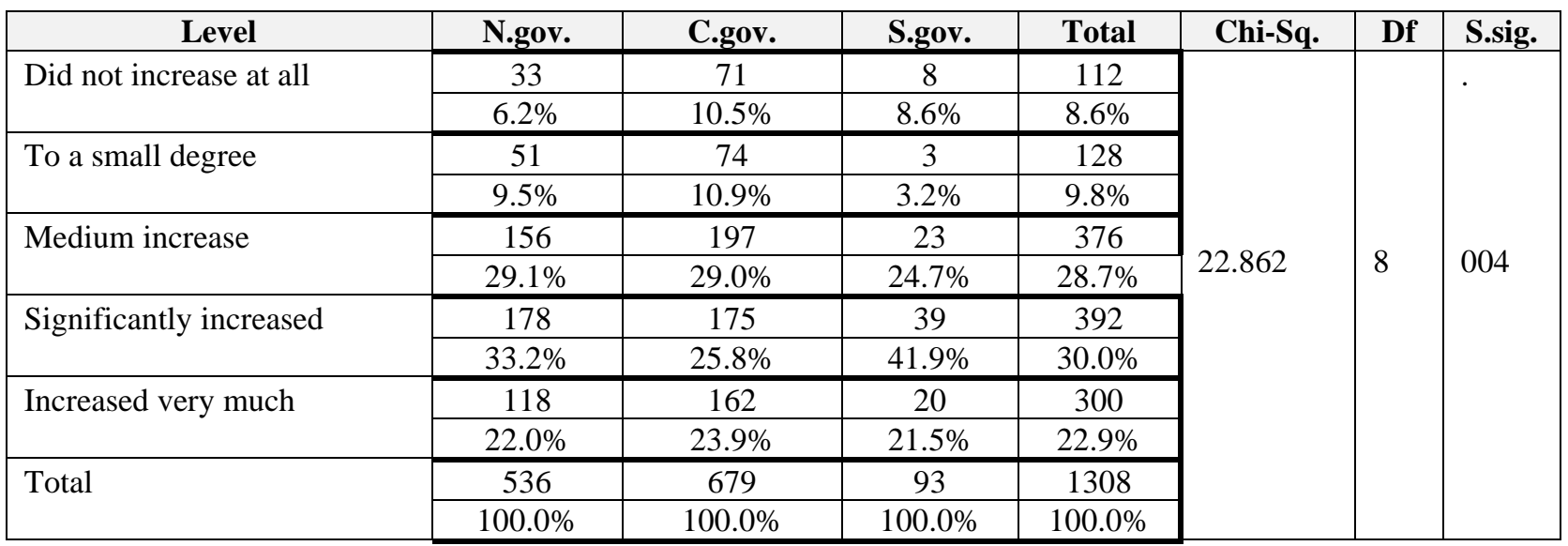

Table (11) shows that the value of chi-squared is equal to (22.862), with a statistical significance of (0.004), which is a statistically significant value at the level of the approved statistical significance $(\alpha=0.05)$. Which means that there is a relationship between the increasing violence of men and the place of residence.

Table (12) Increased men's violence against women during home quarantine and Corona pandemic in light of education level. 


\begin{tabular}{|c|c|c|c|c|c|c|c|}
\hline \multirow[t]{2}{*}{ Did not increase at all } & 8 & 8 & 96 & 112 & \multirow{12}{*}{49.980} & \multirow{12}{*}{8} & \multirow{12}{*}{000} \\
\hline & $40.0 \%$ & $2.5 \%$ & $9.9 \%$ & $8.6 \%$ & & & \\
\hline \multirow[t]{2}{*}{ To a small degree } & 0 & 28 & 100 & 128 & & & \\
\hline & $.0 \%$ & $8.9 \%$ & $10.3 \%$ & $9.8 \%$ & & & \\
\hline \multirow[t]{2}{*}{ Medium increase } & 4 & 108 & 264 & 376 & & & \\
\hline & $20.0 \%$ & $34.2 \%$ & $27.2 \%$ & $28.7 \%$ & & & \\
\hline \multirow[t]{2}{*}{ Significantly increased } & 4 & 108 & 280 & 392 & & & \\
\hline & $20.0 \%$ & $34.2 \%$ & $28.8 \%$ & $30.0 \%$ & & & \\
\hline \multirow[t]{2}{*}{ Increased very much } & 4 & 64 & 232 & 300 & & & \\
\hline & $20.0 \%$ & $20.3 \%$ & $23.9 \%$ & $22.9 \%$ & & & \\
\hline \multirow[t]{2}{*}{ Total } & 20 & 316 & 972 & 1308 & & & \\
\hline & $100.0 \%$ & $100.0 \%$ & $100.0 \%$ & $100.0 \%$ & & & \\
\hline
\end{tabular}

Table (12) shows that the value of chi-squared is equal to (49.980), with a statistical significance of (0.000), which is a statistically significant value at the level of the approved statistical significance $(\alpha=0.05)$. Which means that there is a relationship between men's violence against women and their education level.

Table (13) Increased men's violence against women during home quarantine and Corona pandemic in light of the family's monthly income

\begin{tabular}{|c|c|c|c|c|c|c|c|c|}
\hline Level & $\begin{array}{c}\text { I don't } \\
\text { work }\end{array}$ & - $500 \mathrm{JD}$ & $\begin{array}{c}501-1000 \\
\text { JD } \\
\end{array}$ & $\begin{array}{c}+1000 \\
\mathrm{JD}\end{array}$ & Total & Chi-Sq. & Df & S.sig. \\
\hline \multirow[t]{2}{*}{ Did not increase at all } & 32 & 24 & 36 & 20 & 112 & \multirow{12}{*}{44.823} & \multirow{12}{*}{12} & \multirow{12}{*}{.000} \\
\hline & $8.9 \%$ & $4.8 \%$ & $12.5 \%$ & $12.8 \%$ & $8.6 \%$ & & & \\
\hline \multirow[t]{2}{*}{ To a small degree } & 52 & 40 & 20 & 16 & 128 & & & \\
\hline & $14.4 \%$ & $7.9 \%$ & $6.9 \%$ & $10.3 \%$ & $9.8 \%$ & & & \\
\hline \multirow[t]{2}{*}{ Medium increase } & 100 & 152 & 76 & 48 & 376 & & & \\
\hline & $27.8 \%$ & $30.2 \%$ & $26.4 \%$ & $30.8 \%$ & $28.7 \%$ & & & \\
\hline \multirow[t]{2}{*}{ Significantly increased } & 104 & 144 & 100 & 44 & 392 & & & \\
\hline & $28.9 \%$ & $28.6 \%$ & $34.7 \%$ & $28.2 \%$ & $30.0 \%$ & & & \\
\hline \multirow[t]{2}{*}{ Increased very much } & 72 & 144 & 56 & 28 & 300 & & & \\
\hline & $20.0 \%$ & $28.6 \%$ & $19.4 \%$ & $17.9 \%$ & $22.9 \%$ & & & \\
\hline \multirow[t]{2}{*}{ Total } & 360 & 504 & 288 & 156 & 1308 & & & \\
\hline & $100.0 \%$ & $100.0 \%$ & $100.0 \%$ & $100.0 \%$ & $100.0 \%$ & & & \\
\hline
\end{tabular}

Table (13) shows that the value of chi-squared is equal to (44.823), with a statistical significance of (0.000), which is a statistically significant value at the level of the approved statistical significance $(\alpha=0.05)$. Which means that there is a relationship between men's violence against women and the family's monthly income.

Table (14) Increased men's violence against women during the home quarantine and Corona pandemic in light of the size of the family

\begin{tabular}{|l|c|c|c|c|c|c|c|}
\hline \multicolumn{1}{|c|}{ Level } & $\mathbf{1 - 4} \mathbf{~ p .}$ & $\mathbf{5 - 8} \mathbf{~ p .}$ & $\mathbf{+ 9} \mathbf{~ p .}$ & Total & Chi-Sq. & Df & S.sig. \\
\hline \multirow{2}{*}{ Did not increase at all } & 52 & 44 & 16 & 112 & & \multirow{3}{*}{8} & \multirow{3}{*}{000} \\
\cline { 1 - 6 } & $13.5 \%$ & $5.6 \%$ & $11.4 \%$ & $8.6 \%$ & 83.525 & 8 \\
\hline To a small degree & 52 & 72 & 4 & 128 & & & \\
\hline
\end{tabular}




\begin{tabular}{|l|c|c|c|c|}
\hline & $13.5 \%$ & $9.2 \%$ & $2.9 \%$ & $9.8 \%$ \\
\hline \multirow{2}{*}{ Medium increase } & 92 & 244 & 40 & 376 \\
\cline { 2 - 5 } & $24.0 \%$ & $31.1 \%$ & $28.6 \%$ & $28.7 \%$ \\
\hline \multirow{2}{*}{ Significantly increased } & 100 & 220 & 72 & 392 \\
\hline & $26.0 \%$ & $28.1 \%$ & $51.4 \%$ & $30.0 \%$ \\
\hline \multirow{2}{*}{ Increased very much } & 88 & 204 & 8 & 300 \\
\cline { 2 - 6 } & $22.9 \%$ & $26.0 \%$ & $5.7 \%$ & $22.9 \%$ \\
\hline & 384 & 784 & 140 & 1308 \\
& $100.0 \%$ & $100.0 \%$ & $100.0 \%$ & $100.0 \%$ \\
\end{tabular}

Table (14) shows that the value of chi-squared is equal to (83.525), with a statistical significance of (0.000), which is a statistically significant value at the level of the approved statistical significance $(\alpha=0.05)$. Which means there is a relationship between male violence against women and family size. Table (15) the social causes of man's violence against women during Corona pandemic
in light of the place of residence

\begin{tabular}{|c|c|c|c|c|c|c|c|}
\hline Social factors & N.gov. & C.gov. & S.gov. & Total & Chi-sq. & Df. & S.sig \\
\hline \multirow[t]{2}{*}{ The inferior view to women } & 86 & 49 & 13 & 148 & \multirow{16}{*}{89.986} & \multirow{16}{*}{12} & \multirow{16}{*}{0,000} \\
\hline & $16.0 \%$ & $7.2 \%$ & $14.0 \%$ & $11.3 \%$ & & & \\
\hline \multirow[t]{2}{*}{ The culture of male authority } & 226 & 392 & 38 & 656 & & & \\
\hline & $42.2 \%$ & $57.7 \%$ & $40.9 \%$ & $50.2 \%$ & & & \\
\hline \multirow[t]{2}{*}{ Interfering in others' affairs } & 28 & 20 & 0 & 48 & & & \\
\hline & $5.2 \%$ & $2.9 \%$ & $.0 \%$ & $3.7 \%$ & & & \\
\hline \multirow[t]{2}{*}{ Intervention of parents and relatives } & 123 & 89 & 28 & 240 & & & \\
\hline & $22.9 \%$ & $13.1 \%$ & $30.1 \%$ & $18.3 \%$ & & & \\
\hline \multirow[t]{2}{*}{ Women exercising their personal freedom } & 11 & 41 & 8 & 60 & & & \\
\hline & $2.1 \%$ & $6.0 \%$ & $8.6 \%$ & $4.6 \%$ & & & \\
\hline \multirow[t]{2}{*}{ Women betrayal } & 12 & 7 & 1 & 20 & & & \\
\hline & $2.2 \%$ & $1.0 \%$ & $1.1 \%$ & $1.5 \%$ & & & \\
\hline \multirow[t]{2}{*}{ Woman's lack of experience in dealing with men } & 50 & 81 & 5 & 136 & & & \\
\hline & $9.3 \%$ & $11.9 \%$ & $5.4 \%$ & $10.4 \%$ & & & \\
\hline \multirow[t]{2}{*}{ Total } & 536 & 679 & 93 & 1308 & & & \\
\hline & $100.0 \%$ & $100.0 \%$ & $100.0 \%$ & $100.0 \%$ & & & \\
\hline
\end{tabular}

Table (15) shows that the value of chi-squared is equal to (89.986), with a statistical significance of (0.000), which is a statistically significant value at the level of the approved statistical significance ( $\alpha$ $=0.05)$. Consequently, the social causes of man's violence against women differ according to the place of residence. The results of the chi-square test also showed a relationship between the social factors of man's violence against women and the variables of educational level and the monthly income of the family.

\section{Discussing the results:}


The first question: What are the percentages of battered women in Jordan? Did man's violence against women increase during Corona pandemic? The study found that the actual percentage of battered Jordanian women during Corona pandemic of 2020 was no more than $17.1 \%$ (224 battered women out of 1,308) surveyed, which is less than the statistics issued by (World Health Organization, 2020), (National Commission for Women's Affairs, 2020) and (Petermon \& et al, 2020) study, and the aforementioned low percentage explains that the outbreak of Corona epidemic produced fear, phobias and anxiety among people and families and thus formed a factor of cohesion and harmony more than conflict and violence, which reflected on the actual low rates. While the results of those studies that emphasized the increase in violence against women and domestic violence in Corona pandemic are consistent with the answers of Jordanian women in general (violent and non-violent) who confirmed the increase in violence by men against women during the pandemic between two (high) degrees, considering $35.2 \%$ to (medium) from the perspective of $24.5 \%$, this is in agreement with the study (Al-Majali, 2018) before Corona, less than a quarter of women indicated that it was not increasing.

The study revealed that violence may occur from any man related to a woman and not only by the husband, although husbands practice more violence against their wives by $37.5 \%$, followed by fathers against their daughters by $28.6 \%$, followed by brothers against sisters by $26.8 \%$, and this contradicts the rates of violent practitioners in the Majali study. (2018), and they are husbands by more than $60 \%$, and the rest of the previous studies did not indicate that.

The second question: What are the causes and forms of violence against women in Jordanian society during the Corona pandemic?

Regarding the causes of man's violence against women, the most important social causes were, the culture of male authority prevailing in Arab society, see (Barakat, 2011 and Omar 
2010), and the interference of family and relatives, as well as the inferior view to women. The economic reasons were represented in the difficult living pressures and the low level of family income, both of which reflect poverty. This is consistent with many local and international studies such as Al-Hiasat (2016) as for the health reasons, male violence is due to poor sexual compatibility and to the man's muscular strength. The psychological causes are due to the man's mood and his aggressiveness.

The study found that verbal violence is the most prevalent and practiced against women in Jordan with a rate of $62.2 \%$, followed by physical violence, then psychological violence, and this is completely different from the study result of (Elspeth \& Mirzoev, 2021) which confirmed the most common sexual violence. This is due to the cultural disparity between societies. It also disagrees with (Al-Hiyasat, 2016) study results, which ranked first in sexual violence, while it agrees with (Abdollahi et al, 2021). While the current study was in the last order of forms of violence.

The third question: Are there statistically significant differences on the causes and forms of violence against women in light of Corona pandemic due to variables in place of residence, education, family size and monthly income?

The study found a relationship between man's violence against women, place of residence, monthly family income, family size and level of education. Based on the data that men in tribal and semi-tribal societies in southern Jordan regions are more violent to women compared to men in central and northern societies of Jordan. The battered women are the poorest, the least educated, and those who live in large families are the ones who suffer the most. This is in agreement with (Abdollahi et al, 2021) finding, and with Al-Haysat and Mansour's study (2014), that violence falls on women with little education and in poor families.

\section{Recommendations}


In light of the results, the study recommends the following:

- Establishing social offices whose tasks are to solve problems of domestic violence and enlighten family and community awareness.

- Holding rehabilitation programs, seminars and lectures related to the dangers of domestic violence and the reality on women.

- The government has a duty to solve the issue of the poor economic situation of families as a central factor for the growth of violence against women.

- Enacting targeted legislations and programs to stabilize marital and family life in order to counter violence rates.

Acknowledgment: this research is self-funding and has no financial nor moral support from any party at all. 


\section{References}

Abdollahi, Fatemeh et al (2015). Physical violence against pregnant women by an intimate partner, and adverse pregnancy outcomes in Mazandaran Province, Iran, Journal of Family and Community Medicine,Vol 22, 1. P3-18

Al-Awwada, Amal (2018). Attitudes of social workers towards cases of gender-based violence, Journal of the Islamic University for Human Studies, Vol. 26, No. 2. Pp. 263-292.

Al-Hiyasat, Nadia Ibrahim (2016). The causes and forms of violence against the wife in Jordanian society, "Field Study", Studies, Humanities and Social Sciences, The University of Jordan, Vol. 43, No. 4. pp. 1773-1788

Al-Khashab, Ahmed, 1998 - Family Sociology, Dar Al Ma'rifa, Alexandria.

Al-Khashab. Samia Mustafa. (2008) the Social Theory and the Study of Family. First press. The international house for cultural investment. Cairo.

Al-Khatybeh.Y (2013). The Problems of Jordanian Family in the North of Jordan in the Light of Social Variables, District of AlKoura: A Case Study. Journal of Educational \& Psychological Sciences. University of Bahrain. Vol 14. No.1. pp, 129154.http://dx.doi.org/10.12785/JEPS/140105

Al-Majali, Samih Zaid (2018), Violence against Women in Jordanian Society, “A Field Study in the Karak Governorate", Mu'tah for Research and Studies, Human and Social Sciences Series, Volume 33, Issue 1, pp. 237-288.

Al-Omar, Maan Khalil (2010). Sociology of Violence, First Edition, Dar AshShrooq, Amman. Al-Radiaan, Khaled (2008). Domestic violence against women: A descriptive study on a sample of women in the city of Riyadh, Journal of Security Research, Vol. 17, No. 39. pp. 81-143. 
Al-Zubaidi, Fatimeh (2020).The Socoal, Psycholodical, Economic And Health Effevts Of Divorce On A Sample Of Divorced Women In Amman Governorate, Journal of Archaeology of Egypt, Vol 17, No 6. P 9898 - 9927

Badawi, A. (1986 AD), a Dictionary of Social Sciences Terms, Lebanon Library, Beirut.

Barakat, Halim (1011). Contemporary Arab Society: A sociological survey, Center for Arab Unity Studies, Beirut.

Carron, A, C (2020). Shame, Family Honor, and Dating Abuse: Lessons From an Exploratory Study of South Asian Muslims, Violence Against Women, Vol 26, 15, pp. 20042023 https://doi.org/10.1177/1077801219895115

Dodd, P. (2009). Family Honor and the Forces of Change in Arab Society. International Journal of Middle East Studies, 4 (1), 40-54. Doi: 10.1017/S0020743800027264

Elspeth, Z, Mirzoev, T (2021). Intimate Partner Violence against Indigenous Women in Sololá, Guatemala: Qualitative Insights into Perspectives of Service Providers, Violence against Women, Vol 27. P1-19 https://doi.org/10.1177/1077801220981145

Fawole, Olufunmilayo (2008), Economic Violence to Women and Girls: Is it receiving the necessary attention? Trauma, Violence, \& Abuse, Vol 9, N 3. P167-177 doi.org/10.1177/1524838008319255

Higher Population Council (2020). International Day for the Elimination of Violence against Women, Amman. https://apps.who.int/iris/bitstream/handle/10665/331699/WHO-SRH-20.04-ara.pdf Jordanian Family Protection Department (2020), Family Protection Department data, Amman. Khatayba, Yousef Damen (2018). Marital problems threatening family security in light of some social variables: A social study on husbands working in government departments in Irbid Governorate. Man and Society Journal, University of Tlemcen, Issue 14. pp. 240-269. 
Lotfi, Talaat Ibrahim Al-Zayat, Kamal Abdel Halim (1999) the Contemporary Theory in Sociology, Dar Gharib for Printing, Publishing and Distribution, Cairo.

Majali, Qablan, Al-Qaisi, Salim (2002). Reasons for divorce in Al-Karak Governorate Jordan, Field Study, Journal of the Center for Educational Research, Volume 9, Issue 18, Qatar University, Qatar, pp. 213-173.

Mansour, Essam (2014). Domestic violence in the city of Amman: a field study on battered women from an educational point of view, Journal of Al-Quds Open University for Educational and Psychological Research, Volume 2, No. 7. pp. 207-242.

Naeem, Samir (1996). Theory in Sociology, Dar Al Ma'arif, Cairo.

Petermon, A, \& et al (2020), A Gender Lens on Covid_19 Pandemics and Violence against Women and Ghildren, Center for Global Development. https://www.cgdev.org/blog/gender-lens-covid-19-pandemics-and-violence-againstwomen-and-children

Salibi, Ghassan et al (2020), Coronavirus and its Social Implications for Women, Friedrich Ebert Foundation.

Salibi, Ghassan et al (2020), Coronavirus and its Social Implications for Women, Friedrich Ebert Foundation. http://library.fes.de/pdf-files/bueros/tunesien/16989.pdf

The Jordanian National Commission for Women, (2020). Authority data, Oman.

United Nations Organization (2020), the impact of the COVID-19 pandemic on violence against women and girls in the Arab countries. https://arabstates.unwomen.org/ar/digital-library/publications/2020/12/brief-theimpact-of-covid19-on-vaw-in-the-arab-states-through-the-lens-of-women-csos

World Health Organization (2020), COVID-19 Pandemic and Violence against Women. 
